\title{
Panorama da Gestão Integrada de Recursos Hídricos na Bacia Hidrográfica do Rio Capibaribe-PE
}

Overview of Integrated Water Resources Management in the Capibaribe River Basin-PE

Panorama General de la Gestión Integrada de Recursos Hídricos en la Cuenca Hidrográfica Capibaribe-PE

\author{
Micaella Raíssa Falcão de Moura \\ Professora Doutora, Estácio Recife, Brasil. \\ micaellaraissa@hotmail.com \\ Simone Rosa da Silva \\ Professora Doutora, UPE, Brasil. \\ simonerosa@poli.br \\ Juliana Gomes de Melo \\ Graduanda em Eng. Civil, Estácio Recife, Brasil. \\ juliahgomesmelo@gmail.com
}




\title{
Revista Científica ANAP Brasil
}

\author{
ISSN 1984-3240 - Volume 13, número 31, 2020
}

\section{RESUMO}

As premissas da Política Nacional de Recursos Hídricos (PNRH), bem como os seus instrumentos de gestão, são de fundamental importância para a consolidação de modelos integrados de gerenciamento hídrico. Este artigo tem como objetivo traçar um panorama da Gestão Integrada de Recursos Hídricos (GIRH) na bacia hidrográfica do rio Capibaribe, Pernambuco-Brasil, com base nos instrumentos da Política Nacional de Recursos Hídricos. Para tal, foi realizada uma avaliação do grau de implementação dos cinco instrumentos da PNRH na bacia em estudo: i.Planos de Recursos Hídricos; ii. Enquadramento dos corpos d'água; iii. Outorga; iv. Cobrança e v. Sistemas de informação. A escala de definições desenvolvida permitiu avaliações sobre o grau de implementação dos instrumentos da PNRH, possibilitando análises do panorama geral da GIRH na bacia do Capibaribe. Os resultados mostram que, embora muitos instrumentos tenham avançado, outros ainda se encontram em fase inicial de implementação, refletindo dificuldades observadas em muitas bacias hidrográficas do país no que se refere à consolidação de diretrizes e normativas de governança hídrica.

PALAVRAS-CHAVE: Gestão de Recursos Hídricos. Instrumentos da PNRH. Bacia do rio Capibaribe.

\section{ABSTRACT}

The premises of the National Water Resources Policy (PNRH), as well as its management instruments, are of fundamental importance for integrated water management models consolidation. This article aims to outline an Integrated Water Resources Management (IWRM) panorama in the Capibaribe River basin, Pernambuco-Brazil, based on the National Water Resources Policy Instruments. To this end, an assessment was made of the implementation degree of the five PNRH instruments in the basin under study: i.Water Resources Plans; ii. Framing of water bodies; iii. Water Grant; iv. Water use Charging and v. Information systems. The scale of definitions developed allowed assessments of the implementation degree of the PNRH instruments, enabling analysis of the overall IWRM panorama in the Capibaribe basin. The results show that, although many instruments have advanced, others are still in the initial phase of implementation, reflecting difficulties observed in many river basins in the country regarding the consolidation of water governance guidelines and regulations.

KEYWORDS: Water Resources Management. PNRH instruments. Capibaribe river basin.

\section{RESUMEN}

Las premisas de la Política Nacional de Recursos Hídricos (PNRH), así como sus instrumentos de gestión, son de importancia fundamental para la consolidación de modelos integrados de gestión del agua. Este artículo tiene como objetivo esbozar una visión general de la Gestión Integrada de los Recursos Hídricos (GIRH) en la cuenca hidrográfica del río Capibaribe, Pernambuco-Brasil, basada en los instrumentos de la Política Nacional de Recursos Hídricos. Con este fin, se realizó una evaluación del grado de implementación de los cinco instrumentos PNRH en la cuenca en estudio: i.Planes de recursos hídricos; ii) Enmarcado de cuerpos de agua; iii) Conceder; iv. Colección y v. Sistemas de información. La escala de definiciones desarrollada permitió evaluaciones del grado de implementación de los instrumentos PNRH, permitiendo análisis del panorama general de la GIRH en la cuenca del Capibaribe. Los resultados muestran que, aunque muchos instrumentos han avanzado, otros todavía están en la fase inicial de implementación, lo que refleja las dificultades observadas en muchas cuencas hidrográficas en el país con respecto a la consolidación de las directrices y regulaciones de gobernanza del agua.

PALABRAS CLAVE: Gestión de los recursos hídricos. Instrumentos PNRH. Cuenca del río Capibaribe. 


\section{Revista Científica ANAP Brasil}

ISSN 1984-3240 - Volume 13, número 31, 2020

\section{INTRODUÇÃO}

Ao longo dos séculos, diversas regiões do mundo têm enfrentado problemas relacionados a características climáticas desfavoráveis. No que se refere especificamente à problemática hídrica, os déficits de adaptação às variações hidrológicas somam-se aos atuais desafios e incertezas advindos das mudanças do clima. De forma a atenuar os impactos da variabilidade nos sistemas hídricos, tem sido reforçada a importância do fortalecimento de medidas adaptativas e ajustes dos instrumentos e práticas de gestão de recursos hídricos a essa realidade (ANA, 2016).

Nesse contexto, Castro (2012) afirma que, na América Latina, vários governos têm promovido processos auspiciosos, como a criação de instituições e marcos normativos que podem contribuir potencialmente para um gerenciamento mais racional e equitativo da água. $\mathrm{O}$ autor salienta, entretanto, que um grave risco enfrentado na América Latina é o fato de temas ambientais continuarem a ocupar uma posição ainda muito baixa na escala de prioridades para uma parte significativa dos quadros dirigentes da região.

No Brasil, destaca-se o papel da Lei 9433/97, "Lei das águas", como marco normativo de extrema contribuição e relevância para promoção da gestão participativa com vistas à segurança hídrica do país. Tal Lei reforça o papel do planejamento para a gestão das águas, sendo ainda responsável por implementar a Política Nacional de Recursos Hídricos (PNRH), a qual traz instrumentos de gestão (MOURA; SILVA, 2017). A Lei das águas introduz o conceito de Gestão Integrada de Recursos Hídricos (GIRH), o qual é definido por Cardwell et al. $(2006$, p.9) como um "processo coordenado, direcionado por objetivos, para controlar o desenvolvimento e uso do rio, lago, oceano, pantanal e outros recursos hídricos".

No Estado de Pernambuco, nordeste brasileiro, pode-se observar condutas e decisões políticas que seguem as tendências e ações do governo Federal no tocante ao tema. As políticas governamentais de gerenciamento hídrico em Pernambuco têm sido fortemente embasadas, tendo como suporte um conjunto amplo de dispositivos legais (GOUVEIA; PEDROSA, 2015). Destaca-se, nesse contexto, a Lei Estadual no 12984 de 2005, que prevê a Política Estadual de Recursos Hídricos (PERH) e o Sistema Integrado de Gerenciamento de Recursos Hídricos (SIGRH) (PERNAMBUCO, 2005).

Nessa perspectiva, o presente trabalho tem como objetivo traçar um panorama da GIRH na bacia hidrográfica do rio Capibaribe, Pernambuco-Brasil, com base nos instrumentos da Política Nacional de Recursos Hídricos. A escolha do estudo de caso pauta-se no fato de ser uma bacia estadual com abrangência regional em termos de complexidade do ambiente; e sua extrema relevância para a segurança hídrica e para o desenvolvimento do estado de Pernambuco e especialmente da Região Metropolitana do Recife (RMR).

\section{FUNDAMENTAÇÃO TEÓRICA}

\subsection{Direito à água: aspectos gerais da PNRH e da GIRH em Pernambuco}

O reconhecimento da água como direito humano fundamental é ainda recente e a proteção deste direito exige, além da sua formalização normativa, esforços constantes para sua 


\section{Revista Científica ANAP Brasil}

ISSN 1984-3240 - Volume 13, número 31, 2020

consolidação prática. No panorama mundial, a chamada "Década da Água Potável", período entre 1980 e 1990, marcou o início de maiores conscientizações em torno deste direito. Porém, seu reconhecimento se firmou apenas no ano de 2010, por meio da Resolução 64/292- "O direito humano à água e ao saneamento" - da ONU (AITH; ROTHBARTH, 2015; ONU, 2010).

No Brasil, o processo histórico-jurídico do direito à água possui marcos temporais, tendo início com a promulgação da Constituição Federal de 1988, à qual deu sustentação para o que seria reverberado anos após, em 1997, com a chamada Lei das Águas (9433/97). Destaca-se, entre este período, a realização da Conferência das Nações Unidas sobre o Meio Ambiente e o Desenvolvimento (CNUMAD), no Rio de Janeiro. Também conhecida como Cúpula da Terra, ou ainda Eco-92 e Rio-92, a CNUMAD teve como principal fruto a assinatura da Agenda $21^{1}$, que dispõe em seu capítulo 18 sobre a "Proteção da qualidade e do abastecimento dos recursos hídricos" (BARBOSA; BARBOSA, 2012).

A Lei 9433/97 institui a Política Nacional de Recursos Hídricos, cria o Sistema Nacional de Gerenciamento de Recursos Hídricos (SINGREH) e regulamenta o inciso XIX do art. 21 da Constituição Federal. Entre os objetivos da PNRH, conforme art. 2o da referida Lei, tem-se o de "assegurar à atual e às futuras gerações a necessária disponibilidade de água, em padrões de qualidade adequados aos respectivos usos" (BRASIL, 1997).

Em oposição ao Código de Águas de 1934, o qual apresentava como foco o controle e incentivo do aproveitamento industrial das águas (BRASIL, 1934), a Lei das Águas formaliza os pressupostos da GIRH no Brasil por meio da descentralização administrativa, instituindo a bacia hidrográfica como unidade territorial para implementação da PNRH. Nessa conjuntura, Wolkmer e Pimmel (2013) evidenciam as complexidades adicionadas com este processo, visto que a bacia impõe novas integrações entre as divisões espaciais geopolíticas e os espaços naturais geográficos.

Os autores reforçam, todavia, a importância desta mudança, considerando-se que as bacias hidrográficas constituem as principais formas naturais terrestres dentro do ciclo hidrológico, captando entradas (precipitação) e convergindo-as em saídas de água (escoamento). No que se refere às Competências Constitucionais do direito de legislar sobre as águas no Brasil, estas são gozadas somente pela União e pelos Estados, não possuindo, os municípios, domínio ou titularidade das águas (POMPEU, 2010).

Tratando-se de águas subterrâneas, conforme art. 26 da Constituição Federal2, sua gestão e dominialidade serão sempre do estado. Senra e Hager (2003) falam dos papéis dos estados de São Paulo e Pernambuco, os primeiros a apresentarem legislações específicas acerca do assunto. Nessa perspectiva, muitos autores têm discorrido sobre as fragilidades do arcabouço legal

\footnotetext{
${ }^{1}$ Assinada por 179 países, a Agenda 21 representou um grande marco em prol do desenvolvimento sustentável das nações. No cenário nacional, houve a construção da Agenda 21 Brasileira, que teve sua primeira fase entre 19962002 e foi posteriormente elevada à condição de Programa do Plano Plurianual (PPA 2004-2007). Ressalta-se ainda o Decreto Presidencial de 03 de fevereiro de 2004, que cria a Comissão de Políticas de Desenvolvimento Sustentável e da Agenda 21 Brasileira, e dá outras providências (BRASIL, 2004).

2 No ano de 2000, uma a Proposta de Emenda à Constituição- PEC 43/2000 (BRASIL, 2000a) teve como ementa “Modificar a redação dos artigos 20, III, e 26, I, da Constituição Federal, para definir a titularidade das águas subterrâneas". A PEC foi, no entanto, rejeitada.
} 


\section{Revista Científica ANAP Brasil}

ISSN 1984-3240 - Volume 13, número 31, 2020

brasileiro em termos de águas subterrâneas. Tendo em vista a relevância dos recursos hídricos subterrâneos para a segurança hídrica nacional, verifica-se a urgência de aprofundamentos da PNRH no tocante à temática, especialmente considerando-se as quedas de qualidade das águas superficiais, que têm acrescido demandas descontroladas sobre os aquíferos (HAGER et al., 2002; ALVES JR; HERRMANN, 2016; VILLAR, 2016).

A promulgação da Lei das Águas ampliou as possibilidades de utilização de instrumentos de gestão no país, porém trouxe desafios diversos que vão desde o entendimento desses instrumentos até a sua integração e implementação (SILVA; RIBEIRO, 2006). Nesse sentido, notam-se esforços para medir a implementação dos instrumentos de gestão da PNRH, com casos de estudo na bacia do rio São Francisco (SPINOLA; VITORIA; CERQUEIRA, 2016; BRITO, 2017), na bacia interestadual Piancó-Piranha-Açú (DICTORO; HANAI, 2015) e na lagoa Rodrigo de Freitas (PEREIRA; MEDEIROS, 2009). Na esfera institucional, sublinha-se o Programa de Consolidação do Pacto Nacional pela Gestão das Águas (Progestão), regulamentado por meio da Resolução ANA no 379/2013 (ANA, 2018). A Figura 1 mostra os cinco instrumentos da Política Nacional de Recursos Hídricos:

Figura 1- Instrumentos da PNRH

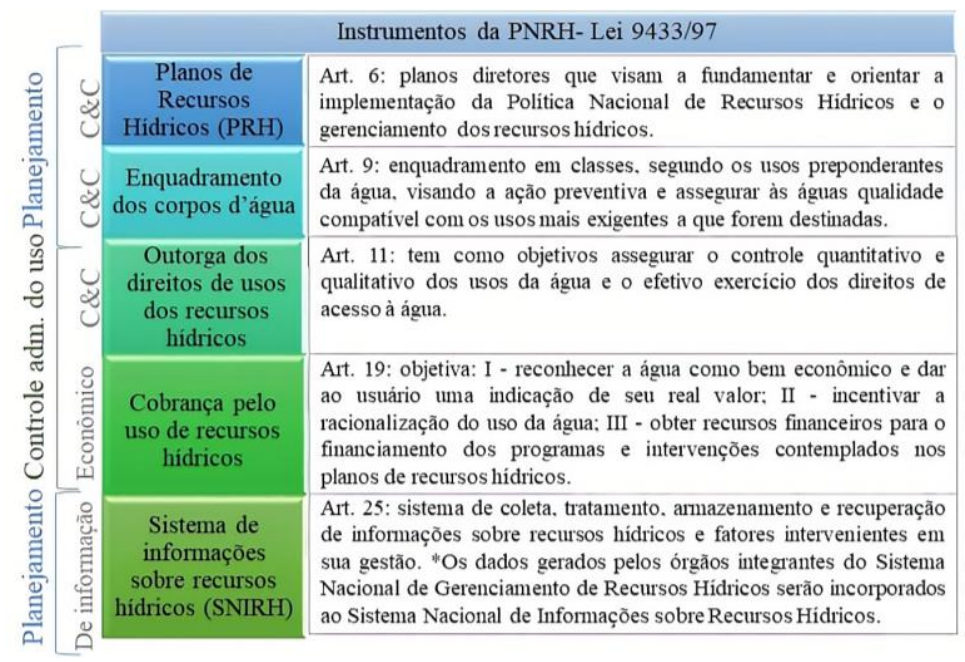

Fonte: As autoras a partir de BRASIL (1997), Moura (2016) e Granziera (2001).

De acordo com Moura (2016), os instrumentos de políticas ambientais no Brasil podem ser classificados em quatro grandes grupos: i) instrumentos regulatórios ou de comando e controle (C\&C); ii) instrumentos econômicos; iii) instrumentos de cooperação e acordos voluntários; e iv) instrumentos de informação. No âmbito da PNRH, a classificação feita pela autora compreende os seguintes grupos:

- C\&C: buscam direcionar o comportamento da sociedade e dos agentes econômicos por meio de permissões ou proibições previamente estabelecidas, baseadas em restrições legais, regulamentações ou normatizações; - Econômicos: direcionam e incentivam indiretamente comportamentos favoráveis ao meio ambiente, por meio de custos ou benefícios associados às alternativas de ação; - De informação: buscam orientar, influenciar ou persuadir os agentes públicos ou privados a atuarem 


\title{
Revista Científica ANAP Brasil
}

\author{
ISSN 1984-3240 - Volume 13, número 31, 2020
}

de forma benéfica ao meio ambiente, por meio da disponibilização de informações e da disseminação de valores favoráveis ao meio ambiente.

(MOURA, 2016, pp. 112-114).

Para Granziera (2001) a divisão destes instrumentos se dá em dois grandes grupos, sendo um relativo ao planejamento e outro referente ao controle administrativo do uso. Já Porto e Porto (2008) afirmam que os instrumentos podem ser enquadrados, de acordo com sua finalidade, em: de disciplinamento (outorga), de incentivo (cobrança) e de apoio (sistemas de informação).

Entre os instrumentos de planejamento, os PRH e o enquadramento dos corpos d'água assumem papéis de destaque quanto à ampliação das possibilidades do planejamento tradicional, tendo em vista as características de construção de consensos por meio de processos participativos. Os PRH devem ser adotados como instrumentos prioritários e de visão de longo prazo, devendo ser elaborados nas escalas nacional, estadual e de bacias- havendo inter-relação entre os planos de diferentes escalas (SANTIN; GOELLNER, 2013; MOURA; SILVA, 2017).

Apesar do reconhecimento como instrumento mais importante da PNRH, Silva (2006) enfatiza que os PRH têm sido elaborados, de maneira geral, por iniciativas isoladas, fator que acentua a desintegração destes instrumentos. Quanto ao enquadramento, este estabelece metas de qualidade dos recursos hídricos pactuadas entre os diferentes atores da bacia. Os critérios sobre a classificação dos corpos d'água, as diretrizes para o enquadramento e as condições e padrões de lançamentos de efluentes encontram-se dispostos na Resolução CONAMA no 357/2005 (ANA, 2016; LUZ; FERREIRA, 2011).

No grupo dos instrumentos de controle administrativo do uso encontram-se a outorga e a cobrança. Segundo Trindade (2016), a outorga visa manter o controle quali-quantitativo dos usos dos recursos hídricos e a garantia do efetivo exercício dos direitos de acesso à água. Único instrumento de natureza econômica, a cobrança, se adequadamente implantada, contribui para garantir a sustentabilidade das bacias, favorecendo mudanças comportamentais dos usuários e usos mais racionais dos recursos hídricos (VERA, 2014; SILVA; RIBEIRO, 2006). "A cobrança está condicionada à existência de outorga, que lhe é precedente, seja ela provisória, seja definitiva" (ROCHA; KHOURY; DAMASCENO, 2018, p. 155).

Acerca do SINGREH, este possui entre seus objetivos, conforme art. 32 da Lei das Águas, implementar a PNRH e arbitrar administrativamente conflitos relacionados aos usos dos recursos hídricos. Integram o SINGREH (art. 33): I - o Conselho Nacional de Recursos Hídricos; IA. - a Agência Nacional de Águas; II - os Conselhos de Recursos Hídricos dos Estados e do Distrito Federal; III - os Comitês de Bacia Hidrográfica; IV - os órgãos dos poderes públicos federal, estaduais, do Distrito Federal e municipais cujas competências se relacionem com a gestão de recursos hídrico e V - as Agências de Água.

Cabe salientar que a Lei 13.844/2019 alterou o disposto na Lei 9.984/2000, e a ANA passou a ser autarquia sob regime especial vinculada ao Ministério do Desenvolvimento Regional (MDR), o qual dispõe de uma Secretaria Nacional de Segurança Hídrica (SNSH).

A figura 2 mostra a estrutura do SINGREH e do Sistema Estadual de Gerenciamento de Recursos Hídricos do estado de Pernambuco 
Figura 2- Sistemas Nacional e Estadual de Gerenciamento Recursos Hídricos

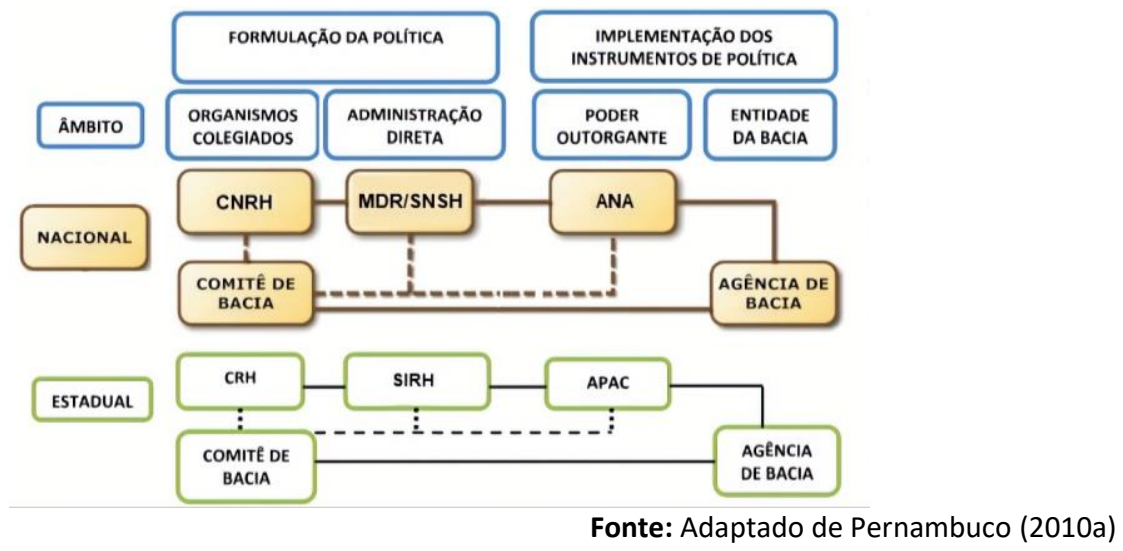

No estado de Pernambuco, a gestão dos recursos hídricos foi legalmente instituída pela Lei estadual 11.426/1997 (PERNAMBUCO, 1997) (revogada pela Lei Estadual no 12984 de 2005), que prevê a Política Estadual de Recursos Hídricos (PERH) e o Sistema Integrado de Gerenciamento de Recursos Hídricos (SIGRH) (PERNAMBUCO, 2005). O arranjo mais recente de gestão hídrica estadual foi consolidado por meio da Lei $\mathrm{n}^{\circ}$ 16.520, de 27 de dezembro de 2018 (PERNAMBUCO, 2018), conforme apresentado na figura 2. Tal Lei dispõe sobre a estrutura e o funcionamento do Poder Executivo estadual e atribui à Secretaria de Infraestrutura e Recursos Hídricos (SIRH) a responsabilidade de "formular e executar as políticas estaduais de recursos hídricos e de saneamento; coordenar o Sistema Integrado de Gerenciamento de Recursos Hídricos do Estado de Pernambuco; implantar e consolidar os instrumentos da política estadual de recursos hídricos" (PERNAMBUCO, 2018, p.1) entre outras atribuições.

Nesse contexto, destaca-se o papel da Agência Pernambucana de Águas e Clima (APAC), que compõe a estrutura descentralizada do Poder Executivo estadual. Criada no ano 2010, através da Lei Estadual no 14.028 (PERNAMBUCO, 2010b), a agência tem como finalidade a execução da $\mathrm{PERH}$ e o controle do uso da água na esfera dos recursos hídricos estaduais e dos federais nos termos delegados. A APAC é autarquia sob regime especial (entidade da administração pública estadual indireta) com personalidade jurídica de Direito Público e autonomia administrativa, técnica e financeira, vinculada à Secretaria de Infraestrutura e Recursos Hídricos de Pernambuco (PERNAMBUCO, 2010b, 2018).

\subsection{A bacia hidrográfica do rio Capibaribe}

A bacia do rio Capibaribe é uma das principais unidades de planejamento hídrico do estado de Pernambuco (UP2), localizando-se na porção nordeste do estado, entre 07 41' 20" e 08 19'30" de latitude sul, e 340 51'00" e 360 41' 58" de longitude oeste. No seu curso de aproximadamente $275 \mathrm{~km}$ desde a sua nascente, entre os municípios de Poção e Jataúba, até a sua foz, na capital Recife, o rio corta 42 municípios, dos quais 15 estão totalmente inseridos na área da bacia, 16 estão parcialmente inseridos e 11 possuem sede na bacia (PERNAMBUCO, 2010c).

A bacia se divide em três macrozonas, MZ-1, MZ-2 e MZ-3, identificadas respectivamente como Alto, Médio e Baixo Capibaribe. No Alto e Médio Capibaribe encontram-se 29 municípios, havendo déficits hídricos. Em decorrência desse fato, além da imperativa necessidade de conservação de água nos leitos arenosos de cursos d'água intermitentes, é essencial a 
importação desse recurso natural, principalmente do rio São Francisco, através de canais e adutoras. Na área do baixo Capibaribe, MZ-3, há um balanço hídrico positivo, visto que as necessidades podem ser atendidas pela produção de água na própria macrozona, necessitando apenas de uma boa gestão dos recursos hídricos em relação à recarga das áreas de aquíferos, controle de poluição e orientação à demanda (BRAGA, 2016; BRAGA et al. 2015).

Há uma alta variabilidade em termos de precipitações na bacia, com valores entre 600 e 2400 $\mathrm{mm}$ ao ano e um total anual médio de aproximadamente $1135 \mathrm{~mm}$. A porção oeste apresenta clima semiárido com $550 \mathrm{~mm} / \mathrm{ano}$ de chuva e temperatura média do ar entre 20 e $22{ }^{\circ} \mathrm{C}$, sendo caracterizada por solos rasos e vegetação de Caatinga (arbustos de espinhos, cactos e gramíneas). Periodicamente esta região sofre com as consequências dos eventos de seca. A parte leste da bacia, por sua vez, é caracterizada por solos mais profundos, vegetação de Mata Atlântica e clima úmido/subúmido, com 2400 mm/ano de chuva e temperatura média do ar entre 25 e $26^{\circ} \mathrm{C}$. Quanto ao regime fluvial, o rio é intermitente em seu alto e médio cursos, tornando-se perene a partir da cidade de Limoeiro (PERNAMBUCO, 2002; RIBEIRO NETO et al., 2014; MOURA et al., 2017).

\section{METODOLOGIA}

De maneira a traçar um panorama da GIRH na bacia do rio Capibaribe, foi realizada extensa revisão bibliográfica e análise documental, bem como consultas junto ao órgão gestor de recursos hídricos do estado. O primeiro passo consistiu na formulação do embasamento teórico em acordo com a temática abordada. Para tal, foram reunidos e catalogados para análise, através do software "Mendeley", artigos científicos, instrumentos jurídicos, entre outros documentos nacionais e internacionais.

Segundo Bardin (1977), a análise documental tem por objetivo, enquanto tratamento de informações contidas num conjunto de documentos, dar uma nova forma e representação a essas informações, de modo a maximizar os aspectos informacionais e de pertinência. Sendo assim, especialmente para elaboração do quadro síntese que traça o panorama da GIRH na bacia, a escala do grau de implementação dos instrumentos baseou-se nos critérios de análise qualitativa de Dutra (2017) e Silva e Silva (2014) (quadro 1): 


\section{Revista Científica ANAP Brasil}

ISSN 1984-3240 - Volume 13, número 31, 2020

Quadro 1- Escala de definições para grau de implementação dos instrumentos de gestão

\begin{tabular}{|c|c|c|}
\hline \multirow{2}{*}{$\begin{array}{c}\text { Grau de } \\
\text { Implementação }\end{array}$} & \multicolumn{2}{|r|}{ Descrição } \\
\hline & Enquadramento dos corpos d'água & Outorga Captação \\
\hline Muito Alto & $\begin{array}{l}\text { Enquadramento implantado há no mínimo } 5 \\
\text { anos; Análises regulares junto ao órgão } \\
\text { ambiental para monitoramento das metas } \\
\text { estabelecidas; }\end{array}$ & $\begin{array}{l}\text { Outorga implantada há no mínimo } 5 \text { anos; } \\
\text { Diagnóstico e Cadastro atualizados- últimos } 5 \text { anos (dos } \\
\text { usuários de águas (superficiais e subterrâneas) na bacia; } \\
\text { Análises regulares de reduções do consumo de água; }\end{array}$ \\
\hline Alto & $\begin{array}{l}\text { Enquadramento implantado há no mínimo } 5 \\
\text { anos; }\end{array}$ & $\begin{array}{l}\text { Outorga implantada há no mínimo } 5 \text { anos; } \\
\text { Diagnóstico e Cadastro dos usuários de águas (superficiais e } \\
\text { subterrâneas) na bacia; }\end{array}$ \\
\hline Médio & $\begin{array}{l}\text { Enquadramento implantado há menos de } 5 \\
\text { anos; }\end{array}$ & $\begin{array}{l}\text { Outorga implantada há menos de } 5 \text { anos; Estudos de } \\
\text { Diagnóstico e Cadastro de usuários. }\end{array}$ \\
\hline Baixo & $\begin{array}{l}\text { Enquadramento em processo de elaboração- } \\
\text { estudo ou proposta em lei- ou submetido à } \\
\text { aprovação do Conselho de } \mathrm{RH} \text {. }\end{array}$ & Outorga implantada há menos de 5 anos; \\
\hline Muito Baixo & $\begin{array}{l}\text { Classes de corpos de água estabelecidas pela } \\
\text { legislação ambiental. }\end{array}$ & $\begin{array}{l}\text { Outorga em processo de implantação- em estudo ou proposta } \\
\text { em lei. }\end{array}$ \\
\hline Não Implementado & Nenhuma ação referente à implantação. & Nenhuma ação referente à implantação. \\
\hline \multirow{2}{*}{$\begin{array}{c}\text { Grau de } \\
\text { Implementação }\end{array}$} & \multicolumn{2}{|r|}{ Descrição } \\
\hline & Cobrança pelo uso - Captação & Sistema de Informações \\
\hline Muito Alto & $\begin{array}{l}\text { Cobrança implantada há no mínimo } 5 \text { anos; } \\
\text { Análises regulares de controle de } \\
\text { arrecadações; Aplicações prioritárias dos } \\
\text { valores arrecadados. }\end{array}$ & $\begin{array}{l}\text { Sistema implantado há no mínimo } 5 \text { anos; } \\
\text { Pesquisas de qualidade operacional do sistema; Coordenação } \\
\text { unificada do sistema. Monitoramento de atualização de } \\
\text { dados e Planejamento anual de modernização do sistema. }\end{array}$ \\
\hline Alto & $\begin{array}{l}\text { Cobrança implantada há no mínimo } 5 \text { anos; } \\
\text { Análises de controle de arrecadações; } \\
\text { Estudos para aplicações prioritárias dos } \\
\text { valores arrecadados. }\end{array}$ & $\begin{array}{l}\text { Sistema implantado há no mínimo } 5 \text { anos; } \\
\text { Análises de pesquisa de qualidade operacional do sistema; } \\
\text { Coordenação unificada do sistema. }\end{array}$ \\
\hline Médio & $\begin{array}{l}\text { Cobrança implantada há menos de } 5 \text { anos; } \\
\text { Análises de controle de arrecadações. }\end{array}$ & $\begin{array}{l}\text { Sistema implantado há no mínimo } 5 \text { anos; Estudos para } \\
\text { análises de pesquisa de qualidade operacional do sistema; }\end{array}$ \\
\hline Baixo & Cobrança implantada há menos de 5 anos. & Sistema implantado há menos de 5 anos. \\
\hline Muito Baixo & $\begin{array}{l}\text { Cobrança em processo de implantação- em } \\
\text { estudo ou proposta em lei. }\end{array}$ & $\begin{array}{l}\text { Sistema em processo de implantação- em estudo ou proposta } \\
\text { em lei. }\end{array}$ \\
\hline Não Implementado & Nenhuma ação referente à implantação. & Nenhuma ação referente à implantação. \\
\hline
\end{tabular}

Fonte: Adaptado de Dutra (2017)

\section{RESULTADOS E DISCUSSÕES}

De acordo com Rocha, Khoury e Damasceno (2018), os instrumentos da PNRH funcionam como peças de uma engrenagem cujo funcionamento completo está condicionado à coexistência de todos esses instrumentos e ao cumprimento de suas respectivas funcionalidades. Mercure et al. (2019) adicionam que, diante do panorama de mudanças globais, muitos mecanismos de gestão da política ambiental brasileira incluem diretrizes integradoras para lidar com o chamado nexus ${ }^{3}$. Araújo et al. (2015) salientam, porém, que, ainda que o modelo brasileiro de gerenciamento hídrico esteja alinhado às tendências internacionais, a implementação dos instrumentos da PNRH requer esforços significativos. Nesse contexto, urge uma compreensão cada vez mais detalhada em torno das relações entre os instrumentos de gestão hídrica. $O$ quadro 2 apresenta uma síntese do panorama da GIRH na bacia do rio Capibaribe considerando-se o grau de implementação dos instrumentos da Política Nacional de Recursos Hídricos.

\footnotetext{
3 "O Nexus Energia-Água-Comida é um dos mais complexos desafios de sustentabilidade enfrentados pelo mundo. Isso é particularmente verdadeiro no Brasil, onde interações pouco compreendidas no Nexus estão contribuindo para o desmatamento em larga escala, para mudanças no uso da terra, escassez de água e energia e para maior vulnerabilidade às mudanças climáticas" (MERCURE et al., 2019, p. 230).
} 
Revista Científica ANAP Brasil

ISSN 1984-3240 - Volume 13, número 31, 2020

Quadro 2- Panorama dos instrumentos da PNRH na bacia do Capibaribe

\begin{tabular}{|c|c|c|c|c|}
\hline Instrumento da PNRH & $\begin{array}{c}\text { Responsabilidade } \\
\text { pela elaboração }\end{array}$ & $\begin{array}{c}\text { Apoio à implementação } \\
\text { (apreciar e aprovar) }\end{array}$ & Corresponsável & $\begin{array}{c}\text { Grau de } \\
\text { implementação }\end{array}$ \\
\hline Plano de $\mathrm{RH}$ & $\begin{array}{l}\text { Agência de Bacia* } \\
\text { APAC }\end{array}$ & COMITÊ DE BH e CRH & COMITÊ DE BH & $\frac{\text { DOIS PLANOS }}{\underline{\text { EXISTENTES }}}$ \\
\hline Enquadramento & $\begin{array}{c}\text { Agência de Bacia* } \\
\text { CRH- definição dos } \\
\text { critérios quantitativos }\end{array}$ & COMITÊ DE BH & $\begin{array}{l}\text { APAC (cadastro dos usuários); } \\
\text { CPRH (critérios ambientais) }\end{array}$ & BAIXO \\
\hline Outorga Captação & SIRH e APAC & - & $\begin{array}{c}\text { CPRH (licenciamento } \\
\text { ambiental) }\end{array}$ & ALTO \\
\hline Cobrança Captação & $\begin{array}{c}\text { SIRH e APAC ou } \\
\text { delegar para Agência } \\
\text { de Bacia* }\end{array}$ & $\begin{array}{c}\mathrm{CRH} \\
\mathrm{COBH}\end{array}$ & $\begin{array}{l}\text { COMITÊ DE BH (propor os } \\
\text { valores a serem cobrados); } \\
\text { CRH (homologação) }\end{array}$ & MUITO BAIXO \\
\hline Sistema de Informações & SIRH e APAC & - & $\begin{array}{c}\text { CPRH (integração } \\
\text { com Sist. Inf. meio ambiente) }\end{array}$ & MÉDIO \\
\hline
\end{tabular}

*Não há Agências de Bacia no estado de Pernambuco.

Fonte: As autoras a partir de Silva e Silva (2014), Dutra (2017) e APAC (2019a).

Com base no exposto no quadro 2, apresentam-se abaixo as discussões:

\subsection{Planos de Recursos Hídricos (PRH)}

Enquanto instrumentos de planejamento da PNRH, os PRH são considerados norteadores da gestão, possuindo caráter multidisciplinar e de construção permanente (WOLKMER; PIMMEL, 2013). A bacia do Capibaribe possui dois Planos, sendo o mais recente o Plano Hidroambiental, de 2010, baseado no PDRH Capibaribe de 2002. Dessa forma, no panorama da GIRH da bacia, a análise documental permitiu concluir que esta apresenta alto grau de implementação em se tratando de PRH quando comparada ao cenário estadual

O PHA Capibaribe mostra-se atualizado em termos de diagnóstico, conteúdos e metas, prevendo em sua estruturação a publicação de relatórios técnicos e a construção de base de dados informacional, sendo composto por cinco Tomos: Tomo I- Diagnóstico hidroambiental da bacia, dividido em três volumes (recursos hídricos; o ambiente natural; socioeconomia e legislação); Tomo II- Cenários Tendenciais e Sustentáveis; Tomo III - Planos de Investimentos; Tomo IVResumo Executivo e Sistematização da Base de Dados e Tomo V- Mapas.

O Tomo III foi formulado como resposta aos diferentes problemas e potencialidades identificados no Diagnóstico Hidroambiental. Os chamados Planos de Investimentos apresentam-se como ações complementares àquelas já implantadas, em fase de implementação ou planejadas para a bacia hidrográfica do rio Capibaribe. Eles foram focados em ações estruturais e não estruturais, segundo três Eixos Temáticos, de modo a ampliar a abrangência dessas ações, como também o acesso aos seus resultados: Eixo I-socioambiental; Eixo II- infraestrutura hídrica e Eixo III- gestão dos recursos hídricos. Os Planos de Investimentos foram planejados para um horizonte de 15 anos, sublinhando-se a explanação:

\footnotetext{
"Tendo como pressuposto a importância da garantia da oferta de água para suprir o abastecimento humano e promover o desenvolvimento socioeconômico, a implantação das ações propostas deverá obedecer a uma lógica sequencial que garanta sinergia ao sistema, considerando os demais programas em desenvolvimento pelo governo do Estado e prefeituras municipais, otimizando as respostas socioambientais no espaço geográfico da Bacia." (Pernambuco 2010d, p. 45).
} 


\section{Revista Científica ANAP Brasil}

ISSN 1984-3240 - Volume 13, número 31, 2020

Cabe salientar, contudo, que, no que se refere aos Planos de Investimentos previstos no PHA, o grau de implementação destes apresenta variações a depender do Eixo temático analisado, conforme investigado por Silva e Silva (2014); Moura et al. (2018) e Moura, Falcão e Montenegro (2019).

\subsection{Enquadramento}

Acerca do instrumento de enquadramento dos corpos de água em classes, segundo os usos preponderantes, este apresentou baixo grau de implementação na bacia, conforme definições dispostas no quadro 1. Por não apresentar proposta aprovada de enquadramento, os corpos de água doce da bacia do Capibaribe enquadram-se na classe 2 , seguindo a orientação da Resolução CONAMA № 357/2005. Segundo art. 4 desta Resolução, as águas doces Classe 2 podem ser destinadas ao abastecimento para consumo humano- após tratamento convencional; à proteção das comunidades aquáticas e à recreação de contato primário, tais como esqui aquático, natação e mergulho.

No âmbito do seu Plano Hidroambiental, a bacia do Capibaribe possui uma proposta preliminar de referência para enquadramento dos corpos hídricos (maior parte de classes 1 e 2), a qual não teve aprovação formalizada pelo comitê (BRAGA et al., 2015). No contexto estadual, a bacia do rio Ipojuca é a única que dispõe de proposta enquadramento aprovada, fato ocorrido na IIā reunião extraordinária do COBH Ipojuca em dezembro de 2019.

Nessa conjuntura, houve o desenvolvimento de pesquisas para elaboração de proposta de referência para enquadramento dos corpos d'água na bacia, conforme apresentado por Silva Junior et al. (2012). A proposta elaborada pelos autores apresenta elevada demanda por corpos hídricos das Classes 1 e 2, sendo desenvolvida também no âmbito do Plano Hidroambiental da bacia. Na escala dos reservatórios, Oliveira et al. (2018) apresentaram a aplicação de um Índice de Conformidade ao Enquadramento (ICE) de maneira a avaliar a condição de um corpo hídrico em relação às metas de enquadramento estabelecidas no reservatório de Jucazinho.

\subsection{Outorga Captação}

O instrumento de outorga (captação) foi o único a apresentar alto grau de implementação na bacia. De acordo com o art. 12 da Lei das Águas, estão sujeitos à outorga pelo Poder Público os direitos dos seguintes usos de recursos hídricos ${ }^{4}$ :

I - Derivação ou captação de parcela da água existente em um corpo de água para consumo final, inclusive abastecimento público, ou insumo de processo produtivo; II Extração de água de aquífero subterrâneo para consumo final ou insumo de processo produtivo; III - lançamento em corpo de água de esgotos e demais resíduos líquidos ou gasosos, tratados ou não, com o fim de sua diluição, transporte ou disposição final; IV - Aproveitamento dos potenciais hidrelétricos; V - Outros usos que alterem o

\footnotetext{
${ }^{4}$ Esta pesquisa avaliou os direitos de uso dos itens I) e II) do referido artigo, tendo em vista a disponibilidade de dados para análise.
} 


\title{
Revista Científica ANAP Brasil
}

\author{
ISSN 1984-3240 - Volume 13, número 31, 2020
}

regime, a quantidade ou a qualidade da água existente em um corpo de água. (BRASIL, 1997, art.12).

A outorga foi implantada no estado de Pernambuco no ano de 1998, exceto para o lançamento de efluentes, sendo, nesta época, concedida pelo então órgão gestor de recursos hídricos e protocolada na Agência Estadual de Meio Ambiente (CPRH). Atualmente compete à APAC, para as águas de domínio estadual, a concessão de outorgas para captação de água dos corpos hídricos e, conforme disposto no art.21 da PERH, este processo é realizado de forma unificada ao licenciamento ambiental. A partir do ano de 2016, todavia, houve o encerramento das atividades do "balcão único" 5 , e os requerimentos de outorga passaram a ser realizados diretamente através do Protocolo da APAC (PERNAMBUCO, 2008; APAC, 2016).

O art. 18 da PERH apresenta as modalidades de outorga, a saber: I) concessão administrativaquando a água se destinar a uso de utilidade pública; e II) autorização administrativa- quando a água se destinar a outras finalidades. $\mathrm{Na}$ bacia do rio Capibaribe prevalece a modalidade de concessão, havendo predominância de emissão de outorgas superficiais entre os anos de 2001 a 2009, tendo-se o baixo Capibaribe (MZ-3) como região de maior número de emissões (SILVA JUNIOR; SILVA, 2014).

A partir do ano de 2010, contudo, passou a prevalecer a emissão de outorgas subterrâneas, estas que, entre os anos de 1998 e 2018, correspondem a cerca de $72 \%$ do número total de outorgas emitidas em Pernambuco e a menos de $5 \%$ do volume total outorgado no estado. A cidade do Recife possui o maior número de poços outorgados, representando $65 \%$ do total de poços cadastrados pela APAC (PERNAMBUCO, 2005; PERNAMBUCO 2010c; SILVA JUNIOR; SILVA, 2014; APAC, 2013, 2019; SIRH, 2019).

A bacia do Capibaribe possuía em 2013 um percentual de 8,6\% das outorgas superficiais de Pernambuco, com finalidade predominante de uso da água para a irrigação (42\%), seguindo-se do abastecimento público (40\%), abastecimento industrial (11\%) e (7\%) para abastecimentos comerciais, pecuária e piscicultura. Para águas subterrâneas, no mesmo ano, entre os titulares de outorgas para captação destacam-se os usuários para abastecimento condominial (59\%) dos usuários outorgados, seguindo-se por abastecimento comercial (18\%) e industrial (9\%). A partir da figura 3, nota-se que os números do ano de 2019- referentes à finalidade predominante de uso para as águas subterrâneas- sofreram poucas alterações quando comparados ao ano de 2013 (APAC, 2013; PERNAMBUCO, 2010c; SIRH, 2019).

Ressalta-se ainda, no contexto da bacia hidrográfica do rio Capibaribe, o contrato de $\mathrm{R} \$$ 1.413.552,35 pago através do PSHPE para realização do diagnóstico de usuários da bacia e cadastro de águas superficiais (rios, reservatórios e lançamento de efluentes) - concluído em 2018. Identificaram-se 682 pontos sujeitos a cadastro, em uma vistoria de 3305 pontos, resultando em um volume total anual captado de 206.299.323,60 $\mathrm{m}^{3}$ (APAC, 2019a). A figura 3 mostra um panorama simplificado do instrumento de Outorga na bacia do rio Capibaribe.

\footnotetext{
${ }^{5} \mathrm{Na}$ chamada atividade de "balcão único" a entrada dos requerimentos de outorga de uso da água e licenciamento ambiental em Pernambuco era realizada unicamente através da Agência Estadual de Meio Ambiente- CPRH (APAC, 2016).
} 
Figura 3- Outorga do uso dos recursos hídricos na bacia do rio Capibaribe

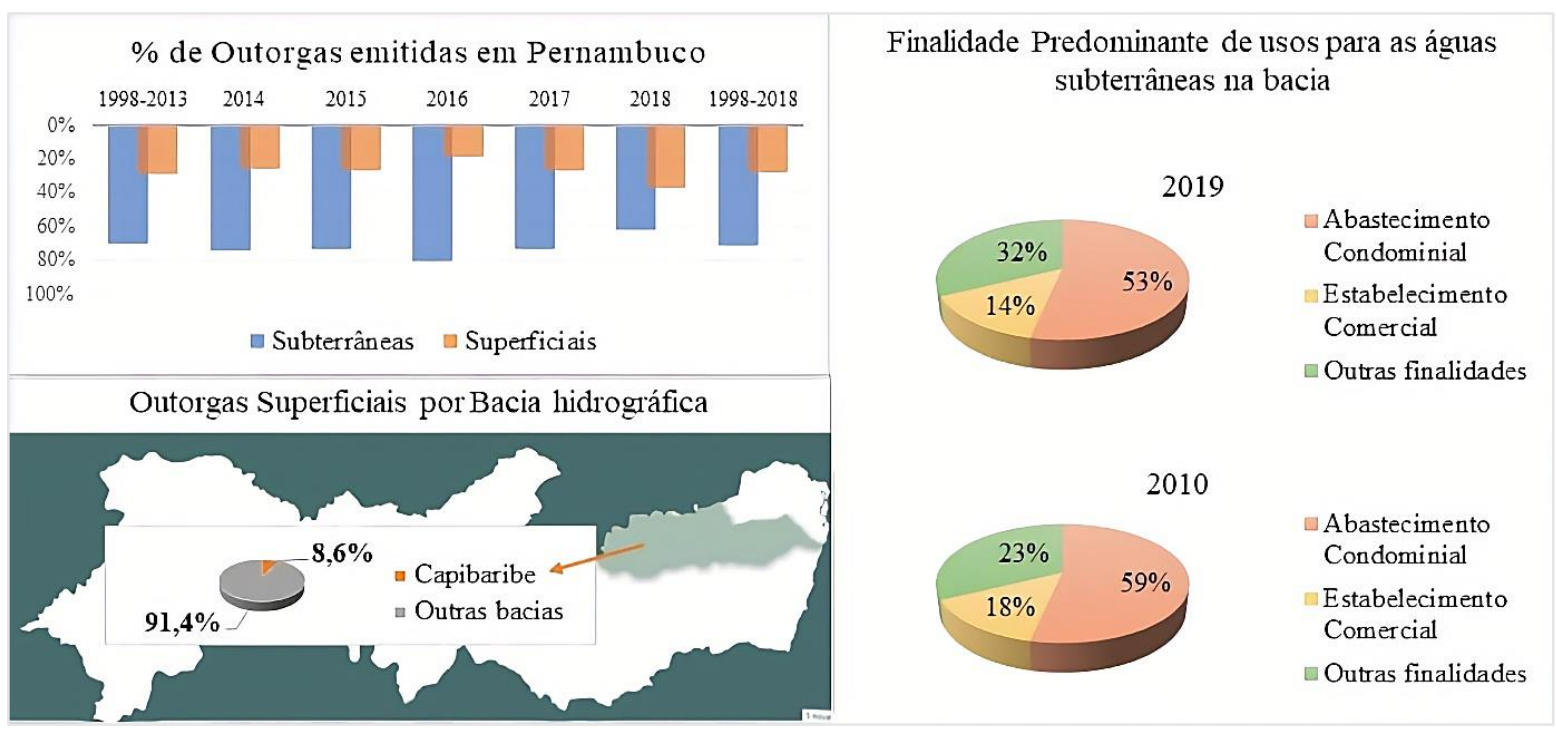

Fonte: As autoras a partir de APAC (2013), PERNAMBUCO (2010c) e SIRH (2019);

\subsection{Cobrança}

Acerca deste instrumento econômico, constatou-se um grau de implementação Muito Baixo na bacia, cabendo destacar que ainda não há implementação da cobrança pelo uso dos recursos hídricos nas águas de domínio de Pernambuco. A PERH se apresenta em conformidade com a PNRH em todos os aspectos de cobrança; entretanto, a Lei Estadual prevê que haja a regulamentação deste instrumento por meio de lei específica. A Política Estadual adiciona ainda que a arrecadação proveniente deste instrumento deverá constituir receita do Fundo Estadual de Recursos Hídricos (FEHIDRO), com aplicação prioritária dos valores na bacia hidrográfica em que estes forem arrecadados, mediante aprovação do respectivo COBH (PERNAMBUCO 2005, 2010c).

Segundo art. 23 da Lei Estadual 12.984/2005, "compete ao órgão gestor de recursos hídricos implantar a cobrança pelo uso da água, ou delegar essa atribuição às Agências de Bacia, cabendo aos COBHs propor os valores a serem cobrados e ao CRH sua homologação". O status atual em torno da cobrança na bacia do rio Capibaribe consiste em aprovação de Projeto de Lei (PL) em reunião extraordinária do $\mathrm{CRH}$ no mês de novembro de 2019. $\mathrm{O}$ quadro 3 mostra um resumo dos estudos de valores de cobrança pelos usos da água em Pernambuco. 
Quadro 3- Valores de estudos da cobrança pelo uso da água em Pernambuco

\begin{tabular}{|c|c|c|}
\hline \multicolumn{3}{|c|}{ Valores de Referência } \\
\hline Tipo de Uso & Unidade & $\begin{array}{l}\mathrm{PPU}_{\text {ref }} \\
\text { (RS) }\end{array}$ \\
\hline Subterrânea & $\mathrm{m}^{3}$ & $\mathrm{R} \$ \quad 0,0500$ \\
\hline Captação de Água Superficial & $\mathrm{m}^{3}$ & RS 0,0360 \\
\hline Vazão de diluição & $\mathrm{m}^{3}$ & $\mathrm{R} \$ \quad 0,0012$ \\
\hline \multicolumn{3}{|c|}{ Valores para cobrir o custeio da APAC } \\
\hline Tipo de Uso & Unidade & $\begin{array}{c}\mathrm{PPU}_{\text {ref }} \\
\text { (R\$) }\end{array}$ \\
\hline Subterrânea & $\mathrm{m}^{3}$ & $\mathrm{R} \$ \quad 0,065$ \\
\hline Captação de Água Superficial & $\mathrm{m}^{3}$ & $\mathrm{R} \$ \quad 0,0468$ \\
\hline Vazão de diluição & $\mathrm{m}^{3}$ & $\mathrm{R} \$ \mathbf{0 , 0 0 1 5 6}$ \\
\hline \multicolumn{3}{|c|}{$\begin{array}{l}\text { Valores para cobrir o custeio da APAC \& Operaçöes das } \\
\text { Infraestruturas Hidricas }\end{array}$} \\
\hline Tipo de Uso & Unidade & $\begin{array}{l}\mathrm{PPU}_{\text {ref }} \\
\text { (RS) }\end{array}$ \\
\hline Subterrânea & $\mathrm{m}^{3}$ & $\mathrm{RS} \quad 0,105$ \\
\hline Captacão de Água Superficial & $\mathrm{m}^{3}$ & $\mathrm{R} \$ \quad 0,0756$ \\
\hline Vazão de diluição & $\mathrm{m}^{3}$ & $\mathrm{R} \$ \quad 0,00252$ \\
\hline
\end{tabular}

Fonte: APAC (2018)

\subsection{Sistema de Informações}

O estado de Pernambuco foi pioneiro no Brasil no que se refere à implementação de um Sistema de Informações sobre Recursos Hídricos- SIRH-PE, sendo este consolidado ainda no ano de 1996, dispondo de recursos SIG, interface gráfica e disponibilidade de acesso pela internet. O sistema foi ainda fundamental para suporte às decisões governamentais e desenvolvimento do primeiro Plano de Recursos Hídricos do estado. Porém, a ausência de estruturas de suporte que promovessem a constante atualização do SIRH-PE causou a sua descontinuidade (PERNAMBUCO, 2008, p.16).

Analisando-se o grau de implementação deste instrumento na escala da bacia do rio Capibaribe, o resultado apontou para uma implementação Média, considerando-se os requisitos dispostos na metodologia. Entre os instrumentos investigados, o SIRH-PE foi o que apresentou maiores dificuldades de obtenção de informações sobre o estado atual de implantação. No contexto geral, faz-se necessário a constante atualização tecnológica do Sistema, o resgate e atualização dos dados e a ampliação/atualização de suas funcionalidades, conforme disposição do Plano Estratégico de Recursos Hídricos e Saneamento do estado (PERNAMBUCO, 2008).

\section{CONSIDERAÇÕES FINAIS}

Diante do exposto, nota-se que a escala de definições desenvolvida permitiu avaliações sobre o grau de implementação dos instrumentos da PNRH, possibilitando análises do panorama geral da GIRH na bacia do Capibaribe. Contudo, são necessários monitoramentos regulares que possibilitem dar maior cobertura aos instrumentos de gestão, considerando, por exemplo, avanços acerca da outorga para lançamento de efluentes ${ }^{6}$ e dos instrumentos adicionais existentes na PERH (fiscalização do uso e monitoramento dos recursos hídricos).

Por consistir em metodologia primordialmente qualitativa, análises similares às realizadas neste trabalho devem ser estimuladas de modo a se tornarem procedimentos regulares no ambiente da gestão integrada dos recursos hídricos- não apenas na bacia em estudo, mas nas demais

\footnotetext{
6 Pinheiro et al. (2013) propuseram uma metodologia de auxílio acerca da outorga para lançamento de efluentes na bacia do rio Capibaribe, com definição de critérios e utilização de modelo de qualidade de água.
} 
Unidades de Planejamento hídrico do estado. Adicionalmente, tais análises devem englobar também estudos de integração entre os níveis de planejamento hídrico, visto que os PRH apresentam as diretrizes em prol da eficiência da gestão integrada das águas.

\section{AGRADECIMENTOS}

As autoras agradecem à APAC, SIRH, UFPE e Centro Universitário Estácio do Recife.

\section{REFERÊNCIAS}

AITH, F.M.A.; ROTHBARTH, R. O estatuto jurídico das águas no Brasil. Estudos Avançados, São Paulo, v. 29, n. 84, p. 163-177, 2015. DOI: 10.1590/s0103-40142015000200011.

ALVES JR.; W.J.F.; HERRMANN, H. Dupla Dominialidade das Águas no Brasil: Entraves Legais para o Adequado Gerenciamento dos Aquíferos. In: XIX Congresso Brasileiro de Águas Subterrâneas. Anais [...]. 2016.

ANA - AGÊNCIA NACIONAL DE ÁGUAS (Brasil). Mudanças Climáticas e Recursos Hídricos: avaliações e diretrizes para adaptação. Brasília, 2016. 93 p. ISBN: 978-85-8210-033-2.

ANA - AGÊNCIA NACIONAL DE ÁGUAS (Brasil). Programa de Consolidação do Pacto Nacional pela Gestão das Águas. Brasília, 2018.

APAC - AGÊNCIA PERNAMBUCANA DE ÁGUAS E CLIMA. A experiência da APAC/PE na análise das outorgas de uso dos Recursos Hídricos em Pernambuco. Apresentação Progestão. 2019a. Disponível:

http://progestao.ana.gov.br/portal/progestao/. Acesso em: 29 out. 2019.

APAC - AGÊNCIA PERNAMBUCANA DE ÁGUAS E CLIMA. Banco de dados. Notícias. 2016. Disponível em: http://www.apac.pe.gov.br/noticias.php?noticia id=859. Acesso em: 29 set. 2019.

APAC - AGÊNCIA PERNAMBUCANA DE ÁGUAS E CLIMA. Relatório de situação de recursos hídricos do Estado de Pernambuco 2011/2012. Recife: Apac, 2013. 116p. Disponível:www.lai.pe.gov.br/apac/. Acesso em: 29 set. 2019.

ARAÚJO, R.S.; ALVES, M.G.; CONDESSO DE MELO, M.T.; CHRISPIM, Z.M.P.; MENDES, M.P.; SILVA JÚNIOR, G.C. Water resource management: A comparative evaluation of Brazil, Rio de Janeiro, the European Union, and Portugal. Science of The Total Environment, v. 511, 815-828, abr. 2015. DOI: 10.1016/j.scitotenv.2014.11.098.

BARBOSA, E.M.; BARBOSA, M.F.N. Direito de águas: arranjo jurídico-institucional, política e gestão. Revista de Informação Legislativa, Brasília, v. 49, n. 194, p. 147-157, abr./jun. 2012. Disponível em: https://www2.senado.leg.br/bdsf/handle/id/496926. Acesso em: 29 jan. 2019.

BARDIN, L. Análise de conteúdo. Lisboa, Edições 70, 1977.

BRAGA, R. A. P. Águas de Areias. 1. ed. Recife: Ed. Clã. 2016. 366p.

BRAGA, R.A.P.; FARIAS, C.R.O.; SILVA, S.R.; CAVALCANTI, E.R. Gestão e educação socioambiental na Bacia do Capibaribe. 1. ed., Recife: editora Clã, 2015. 140 p.

BRASIL. Presidência da República. Decreto no 24.643, de 10 de julho de 1934. Decreta o Código de Águas. Diário Oficial da República Federativa do Brasil, seção 1, Brasília, DF, 10 jul. 1934.

BRASIL. Poder Executivo. Lei no 9.433/1997. Instituiu a Política Nacional de Recursos Hídricos. Diário Oficial da República Federativa do Brasil, Brasília, DF, 09 jan. 1997.

BRASIL. Presidência da República. Decreto Presidencial de 03 de fevereiro de 2004. Cria, no âmbito da Câmara de Políticas dos Recursos Naturais, do Conselho de Governo, a Comissão de Políticas de Desenvolvimento Sustentável e da Agenda 21 Brasileira, e dá outras providências. Diário Oficial da República Federativa do Brasil, Poder Executivo, Brasília, 2004.

BRITO, Y.M.A. Níveis de implementação da Política Nacional de Recursos Hídricos: um comparativo entre a bacia do rio São Francisco e a bacia do rio Salitre-BA. Dissertação (Mestrado em Recursos Naturais). Universidade Federal de Campina Grande. Campina Grande, PB, 85 p. 2017.

CARDWELL, H.E.; COLE, R.A.; CARTWRIGHT, L.A.; MARTIN, L.A. Integrated water resources management: definitions and conceptual musings. Journal of Contemporary Water Research \& Education, v. 135, p. 8-18, dez. 2006. DOI: 10.1111/i.1936-704X.2006.mp135001002.x. 


\title{
Revista Científica ANAP Brasil
}

\author{
ISSN 1984-3240 - Volume 13, número 31, 2020
}

CASTRO, J.E. A gestão da água na América Latina. 2012. IPEA. Disponível em:

http://desafios.ipea.gov.br/index.php?option=com content\&view=article\&id=2834\%3Acatid=28\&ltemid=23.

DICTORO, V. P.; HANAI, F. Y. Implementação, efetividade e conhecimento dos instrumentos da PNRH na bacia hidrográfica Piancó-Piranha-Açú: uma visão de alguns membros do seu respectivo comitê. In: XXI Simpósio Brasileiro de Recursos Hídricos, 2015, Brasília - DF. Anais eletrônicos [...], 2015.

DUTRA, M.T.D. Desenvolvimento de um índice de sustentabilidade hidroambiental em bacia hidrográfica: $\mathbf{o}$ caso da bacia do rio Capibaribe, Pernambuco. Tese (Doutorado em Engenharia Civil). Universidade Federal de Pernambuco, 2017. $160 \mathrm{f}$.

GOUVEIA, R.L.; PEDROSA, I.V. Gestão das Políticas Governamentais para os Recursos Hídricos, Recife, Pernambuco, Brasil. Desenvolvimento em Questão, v. 13, n. 32, p. 103-126, 2015.DOI: 10.21527/22376453.2015.32.103-126

GRANZIERA, M.L. Direito de águas: disciplina jurídica das águas doces. São Paulo: Atlas, 2001.

HAGER, F. P.V.; SILVA, J.R.C.; ALMEIDA, W.M.; OLIVEIRA, W.A. A Problemática da Gestão das Águas Subterrâneas no Brasil. In: XII Congresso Brasileiro de Águas Subterrâneas, Anais eletrônicos [...], 2002.

LUZ, L. D.; FERREIRA, M. T. A questão ecológica na gestão dos corpos hídricos - analisando os focos das diretrizes brasileira e europeia. Revista de Gestão da Água da América Latina (REGA), v.8, n. 1, p.19-31, 2011. DOI: 10.21168/rega.v8n1.p19-31

MERCURE, J.F.; PAIM, M. A.; BOCQUILLON, P.; LINDNER, S.; SALAS, P.; MARTINELLI, P.; ... VINUALES, J. E. System complexity and policy integration challenges: The Brazilian Energy- Water-Food Nexus. Renewable and Sustainable Energy Reviews, v. 105, p. 230-243, 2019. DOI:10.1016/j.rser.2019.01.045

MOURA, A. M. M. Aplicação dos instrumentos de política ambiental no Brasil: avanços e desafios. In: Moura, Adriana M.M. (Org.). Governança ambiental no Brasil: instituições, atores e políticas públicas. 1. ed. Brasília: Ipea, 2016, v. único, p. 111-146, 2016.

MOURA, M. R. F., RIBEIRO NETO, A., SANTANA, M. C. N., CAMPOS, B. V. R., MONTENEGRO, S. M. G. L. Hydrological variability in the Capibaribe River Basin in the 20th and 21st centuries. In: XVI World Water Congress, 2017, Cancun. Anais [...] Proceedings of XVI World Water Congress, 2017.

MOURA, M.R.F.; FALCÃO, S. M. P.; MONTENEGRO, S.M.G.L. Proposta de articulação intermunicipal para monitoramento das ações previstas no Plano Hidroambiental da bacia do rio Capibaribe-PE. In: Simpósio Brasileiro Online de Gestão Urbana (SIBOGU), 2019. Anais [...] do III SIBOGU, 2019.

MOURA, M.R.F.; MONTENEGRO, S.M.G.L.; RIBEIRO NETO, A.; SILVA, S.R., Challenges of watershed hydroenvironmental master plans (case study), In: NOLASCO. M.; CARISSIMI, E.; URQUIETA-GONZALES, E. (Org.). Water perspectives in Emerging Countries - Linking water security to Sustainable Development Goals. 1ed.Göttingen: Cuvillier Verlag, v. 1, p. 40-53, 2018.

MOURA, M.R.F.; SILVA, S.R. Lei das águas e a gestão dos recursos hídricos no Brasil: contribuições para o debate. Periódico Eletrônico Fórum Ambiental da Alta Paulista, [s.l.], v. 13, n. 3, p.15-24, 19 dez. 2017. ANAP - Associação Amigos de Natureza de Alta Paulista.

MOURA, M.R.F.; SILVA, S.R. Lei das águas e a gestão dos recursos hídricos no Brasil: contribuições para o debate. Periódico Eletrônico Fórum Ambiental da Alta Paulista, v. 13, n. 3, p.15-24, 19 dez. 2017.

OLIVEIRA, I. S.; PANTA, L. M.; BARBOSA, I. M. B. R.; SILVA, S. R. Índice de Conformidade ao Enquadramento nos Reservatórios Jucazinho, Bituri, Botafogo e Pirapama, em Pernambuco, Brasil. Revista Brasileira de Geografia Física v. 11, n.4, p. 1575-1584, 2018. DOI: 10.26848/rbgf.v11.4.p1575-1584

ONU - ORGANIZAÇÃO DAS NAÇÕES UNIDAS. Resolução A/RES/64/292. 2010. Disponível em: https://undocs.org/en/A/RES/64/292. Acesso em: 20 mar. 2019.

PEREIRA, R. M. V.; MEDEIROS, R. A aplicação dos instrumentos de gestão e do Sistema de Gerenciamento dos Recursos Hídricos na Lagoa Rodrigo de Freitas, RJ, Brasil. Revista Ambiente \& Água, v.4, n.3, p.211-229, 2009. DOI: $10.17265 / 2161-6256 / 2015.06 .004$

PERNAMBUCO. Lei no 11.426, de 17 de janeiro de 1997. Dispõe sobre a Política Estadual de Recursos Hídricos, e o Plano Estadual de Recursos Hídricos, institui o Sistema Integrado de Gerenciamento de Recursos Hídricos e dá outras providências. Diário Oficial do Estado de Pernambuco: Pernambuco, 1997.

PERNAMBUCO. SRH - Secretaria de Recursos Hídricos. Plano Diretor de Recursos Hídricos da Bacia Hidrográfica do Rio Capibaribe. Recife: SRH, 2002. 
PERNAMBUCO. Lei no 12.984, de 30 de dezembro de 2005. Dispõe sobre a Política Estadual de Recursos Hídricos e o Sistema Integrado de Gerenciamento de Recursos Hídricos, e dá outras providências. Diário Oficial do Estado de Pernambuco: Pernambuco, 2005.

PERNAMBUCO. Secretaria de Recursos Hídricos. Plano Estratégico de Recursos Hídricos e Saneamento. CARVALHO, A. X. (Coord. téc.). Recife: A Secretaria, 2008. 112 p.

PERNAMBUCO. SRH - Secretaria de Recursos Hídricos. Plano Hidroambiental da bacia Hidrográfica do rio Capibaribe: Resumo executivo. Projetos Técnicos. Pernambuco, Secretaria de Recursos Hídricos, 2010a. 100 p.

PERNAMBUCO. Lei no 14.028, de 26 de março de 2010. Cria a Agência Pernambucana de Águas e Clima - APAC, e dá outras providências. Diário Oficial do Estado de Pernambuco: Pernambuco, 2010b.

PERNAMBUCO. SRH - Secretaria de Recursos Hídricos. Plano Hidroambiental da Bacia Hidrográfica do Rio Capibaribe (Tomo I - Diagnóstico Hidroambiental- Recursos Hídricos - Volume 01/03). Recife, 2010c, 394p.

PERNAMBUCO. SRH - Secretaria de Recursos Hídricos. Plano Hidroambiental da Bacia Hidrográfica do Rio Capibaribe (Tomo III - Planos de Investimentos). Recife, 2010d, 291p.

PERNAMBUCO. Lei $n^{\circ} 16.520$, de 27 de dezembro de 2018. Dispõe sobre a estrutura e o funcionamento do Poder Executivo. Diário Oficial do Estado de Pernambuco: Pernambuco, 2018.

PINHEIRO, R. B.; MONTENEGRO, S.G.; SILVA, S.R. MEDEIROS, Y.D.P.; AURELIANO, J.T. Outorga para Lançamento de Efluentes? Uma Metodologia de Apoio à Gestão de Recursos Hídricos. Revista Brasileira de Recursos Hídricos, $v$. 18, p. 55-65, 2013. DOI: 10.21168/rbrh.v18n4.p55-65

POMPEU, C.T. Direito de águas no Brasil. 2.ed. São Paulo: Editora Revista dos Tribunais, 2010.

PORTO, M. F. A.; PORTO, R. L. Gestão de bacias hidrográficas. Estudos Avançados, v. 22, n. 63, p.43-60, 2008.

RIBEIRO NETO, A.; SCOTT, C. A.; LIMA, E. A.; MONTENEGRO, S. M. G. L.; CIRILO, J. A. Infrastructure sufficiency in meeting water demand under climate-induced socio hydrological transition in the urbanizing Capibaribe River basin - Brazil. Hydrology and Earth System Sciences, v. 18, p. 3449-3459, 2014. DOI: 10.5194/hess-18-3449-2014

ROCHA J. C. S.; KHOURY L. E. C.; DAMASCENO A. P. D. Direito das águas - trajetória legal, conflitos e participação social. Revista de Direito Sanitário, v. 18, n. 3, p.143-166, 22 mar. 2018. DOI: 10.11606/issn.2316-9044.v18i3p143$\underline{166}$.

SANTIN, J. R.; GOELLNER, E. A Gestão dos recursos hídricos e a cobrança pelo seu uso. Sequência (Florianópolis), v.34, n.67, p.199-221, 2013. DOI:10.5007/2177-7055.2013v34n67p199.

SENRA, J. B.; HAGER, F. P. V. Águas subterrâneas e a legislação de recursos hídricos. In: XIII Encontro Nacional de Perfuradores de poços e I Simpósio de Hidrogeologia do Sudeste. Anais [...]. Petrópolis: abas, p. 83 - 90, 2003.

SILVA JUNIOR, M. A. B.; SILVA, S. R.; BARROS, A. M. L.; ALCOFORADO, R. M. G.; ASFORA, M. Estudo para elaboração da proposta de referência para enquadramento dos corpos d'água na bacia hidrográfica do rio Capibaribe, Pernambuco. In: XI Simpósio de Recursos Hídricos do Nordeste, 2012, João Pessoa. Anais [...] João Pessoa: Ed. Universitária; Campinas, SP: Autores Associados, 2012.

SILVA JUNIOR, M.A.B.; SILVA, S. R. A outorga de direito de uso dos recursos hídricos na bacia hidrográfica do rio Capibaribe, Pernambuco-Brasil. In: XII Simpósio de Recursos Hídricos do Nordeste, 2014, Natal. Anais [...] 2014.

SILVA, A.P.; SILVA, C.M. Planejamento ambiental para bacias hidrográficas: convergências e desafios na bacia do rio Capibaribe, em Pernambuco-Brasil. Holos, v. 1, p.20-40, 31 jan. 2014.

SILVA, R.O.B.D.; MONTENEGRO, S.M.G.L.; SOUZA, W.M. Tendências de mudanças climáticas na precipitação pluviométrica nas bacias hidrográficas do estado de Pernambuco. Engenharia Sanitária e Ambiental, v. 22, n.3, p. 579-589, 2017. DOI:10.1590/s1413-41522017142481

SILVA, S. R. A integração entre os níveis de planejamento de recursos hídricos - estudo de caso: a bacia hidrográfica do rio São Francisco. 2006. 301 f. Tese (Doutorado em Engenharia Civil) - Universidade Federal de Pernambuco, Recife, 2006.

SILVA, S.C.; RIBEIRO, M. M. R. Enquadramento dos corpos d'água e cobrança pelo uso da água na bacia do rio Pirapama - PE. Engenharia Sanitária e Ambiental, v. 11, n. 4, p.371-379, 2006.

SIRH - SECRETARIA DE INFRAESTRUTURA E RECURSOS HÍDRICOS DE PERNAMBUCO. Planilhas de Outorga Superficial e Subterrânea. Recife, 2019. 


\title{
Revista Científica ANAP Brasil
}

\author{
ISSN 1984-3240 - Volume 13, número 31, 2020
}

SPÍNOLA, C.A.; VITORIA, F.; CERQUEIRA, L. A Lei das Águas e o São Francisco: os limites da gestão descentralizada dos recursos hídricos no brasil. Rde - Revista de Desenvolvimento Econômico, v. 1, n. 39, p.70-90, abr. 2016. DOI: 10.21452/rde.v1i33.4176.

TRINDADE, L.L. Gestão Integrada de Recursos Hídricos: papel, potencialidades e limitações dos comitês de bacias hidrográficas. 2016. 269 f. Tese (Doutorado em Ciências Humanas). Universidade Federal de Santa Catariana, Santa Catarina, 2016.

VERA, L.H.A. Atuação da cobrança pelo uso da água de domínio da união como instrumento de gestão de recursos hídricos na Bacia Hidrográfica do Rio São Francisco. 2014. 165 f. Dissertação (Mestrado em Engenharia civil Tecnologia ambiental e Recursos Hídricos). Universidade Federal de Pernambuco -UFPE, 2014.

VILLAR, P. C. Groundwater and the Right to Water in a Context of Crisis. Ambiente \& Sociedade, v.19, n.1, 85-102, 2016. DOI:10.1590/1809-4422asoc150126r1v1912016

WOLKMER, M. D. F.; PIMMEL, N. F. Política Nacional de Recursos Hídricos: governança da água e cidadania ambiental. Sequência: Estudos Jurídicos e Políticos, v. 34, n. 67, p.165-198, 2013. DOI:10.5007/2177-

7055.2013v34n67p165 